\title{
Interlink of Road: Opposite Dimensions of Social and Environmental Impacts in Mountain Region
}

\author{
Dr Shukra Raj Adhikari \\ Associate Professor and Head \\ Department of Social Work \\ Tribhuvan University, Nepal \\ Co-author Er. Bibek Thakali
}

\begin{abstract}
Road infrastructures play an important role in the overall development of rural areas. The intervention of transport infrastructures has wide potential to reach and enhance that sector of the rural population. Thus this article is focused to find out the influence of road in interaction patterns, service delivery, indigenous practices, and the environment in the mountain regions. For this, the information is carried out through comprehensive fieldwork of Jomsom rural municipality of Mustang district which represents the high mountain region of Nepal. This article is based on a qualitative research approach. Primary data are collected by the case study method. Secondary data are collected from previous literature through the content analysis. The content analysis method is used to analyze both primary and secondary data. Road transportation is the breakthrough for women enhancement, community participation, social interaction, and service delivery. But environmental challenges and degradation in the mountain regions.
\end{abstract}

Keywords:- Community, environment, interaction, road, service delivery.

\section{INTRODUCTION}

Road infrastructure development influences lands and settlements as well as exerts pressure on local resources and the ecosystem. It intervents both the terrestrial and aquatic ecosystem and displaces the people from their settlements and it also directly or indirectly influences the social, economic, cultural, biological, and physical environment. Moreover, some impacts could have residual effects for a long duration and some impacts could be realized only during the operation phase of the road project. There is a close link between rural connecting roads and poverty reduction through an increase in income opportunities to rural people. The development market linkage, in other words, network development helps them diversify their income sources as they have linked with more variety and functional livelihood value chain systems. This circulation influence the interaction between rural and urban social structure, income; living standards, indigenous practices and environment (Golmohammadi, 2012).

The history of the development of roads in Nepal is not very long. It was obvious in 1924 that the first road development program was initiated in the country. About 2 to $3 \mathrm{~km}$ of paved road was constructed in Kathmandu valley at that time. $42 \mathrm{~km}$ long all-weather gravel road linking Amlekhganj with Bhimphedi was built in 1929. Nepal, before the establishment of democracy in 1951, had the paved road only in Kathmandu and it was limited to about 2 or 3 kilometers in length. There were unpaved road network in Kathmandu but were not designed for motor vehicles. There were unbuilt road tracks in the Terai (southern plain) and they were used only in dry seasons. The rest of the country, that is the hills and the mountains, had only foot trails and mule tracks. "Mul Batos" or "Hulaki batos" were the official main arteries of trails. After the storage of democracy from 1951 to 2012, the road infrastructure was developed appreciably in amount. The authoritative role for the road infrastructure had been shouldered by the Public Works Department, which is restructured to the Department of Roads in 1970, however, some other agencies were also often involved in the task of road construction. The first long-distance road to link Kathmandu with the Terai was taken up in 1953 with the Indian assistance. This $115 \mathrm{~km}$ long road between Thankot of Kathmandu and Bhainse was opened to traffic in 1956. The decade of 1960 to 1970 is a milestone in the construction of the highway in Nepal. Second highway Siddhartha Rajmarga connecting Sunauli and Pokhara was constructed by the Government of India in this period. The earlier policy of emphasizing north-south roads was replaced by the east-west roads like the East-West Highway (1026 km), Prithivi Raj Marg (Kathmandu - Pokhara, 176 km) and Araniko Raj Marg(GON, 2017). Before 1990 District Panchayats were also playing some role as an authority in constructing roads of local nature, but it was not that institutionalized as to take the overall responsibility of it. After the people's movement of the 1990's, the road network is classified as a strategic road network (SRN) and a local road network (LRN). SRN (Highways and feeder roads) was under the responsibilities of DOR and LRN (District Roads and Village Roads, which are also called rural roads) was under the responsibilities of local institutions i.e DDC and VDC. The construction of rural roads geared at high speed after the decentralization of rural roads construction LGCDP. (2011). The Department of Road's Priority Investment Plan II 2007-2016 (PIP-II) indicates that about 39 percent of people in the Hills and Mountains are more than a four-hour walk away from the nearest all-weather road, 10 percent of the plains population is beyond the two hours limit. In extreme cases in the High Himalayas and Mountains, even today it can take up to 13 days to walk to the nearest road head (NPC, 2011). 
Access to roads, market places, health facilities, administrative centers and schools among other are essential requirements of the rural population. Government efforts to develop rural transport infrastructure has increased in the last decade in Nepal. At present, most of the villages have access to motor tracks. By reducing the transport cost, roads are expected to generate market activity, affect input and output prices and foster economic linkages that enhance agricultural production, alter land use, crop intensity and other production decision, stimulate off- farm diversification and other income generating opportunities and encourage migration (Van de Walle, 2008). Road may have significant adverse, short-term and long term environmental impacts. Some of the most significant adverse impacts of road activities are soil erosion, degraded water quality, deforestation and uncontrolled settlement, ecosystem and habitat damage, declines in scenic quality, health and safety concerns, local culture etc. Many of these adverse impacts of road projects can be avoided or minimized by applying environmentally sound design, construction, and operation and maintenance practices (USAID, 2008).

Jomsom a headquarter of Mustang district which is a major growth center evolved after Baglung Jomsom Rural Road and among one of Mustang district, also known as Dzong-Sampa or New Fort, is a town located at an altitude of about $2700 \mathrm{~m}$ in Mustang District, Nepal. It extends over both the banks of the Kali Gandaki River. Geographically,
Jomsom lies in the Trans-Himalaya rain shadow zone. Before invasion of Tibet by Chinese army in 1959 this was the famous salt trading route between Nepal, Tibet and India. Thakalis and Gurung are the dominant ethnic community of Jomsom Rural Municipality but other castes like Bhrahmin, Chettri and other are also in some numbers. However, it has witnessed important changes after the opening of Beni-Jomsom Road, from a traditional Thakali village to a multifunctional and multiethnic town settlement. Jomsom Rural Municipality of three villages i.e Jomsom, Thini and Dhumba. At present, Jomsom is becoming more commercial centre day-by-day where the tourism and agriculture are prominent business. Since this is also district headquarter of Mustang, all the government activities and services are found in Jomsom. Since the establishment of district headquarters as Jomsom in 1970s, the government has made a significant investment to improve basic services in Mustang. The airport operating since early 1970s handles 50000 passengers every year (DDC, 2059) from Pokhara to Jomsom. There are about 30 government offices in Jomsom. The literacy rate is $75.72 \%$ which highest than others. Culturally this area is dominant by Thakalis and most people in the area are Buddhists. For maintaining the peace, order and social harmony -Mukhiyall system is prominent. Traditionally people have been subsistence farmers but now a day's tourism has become an important economic factor as well. The major agricultural and tourism products are Buckwheat, Barley, Maize, Apple, Apricot, Walnut, Potatoes handicrafts etc.

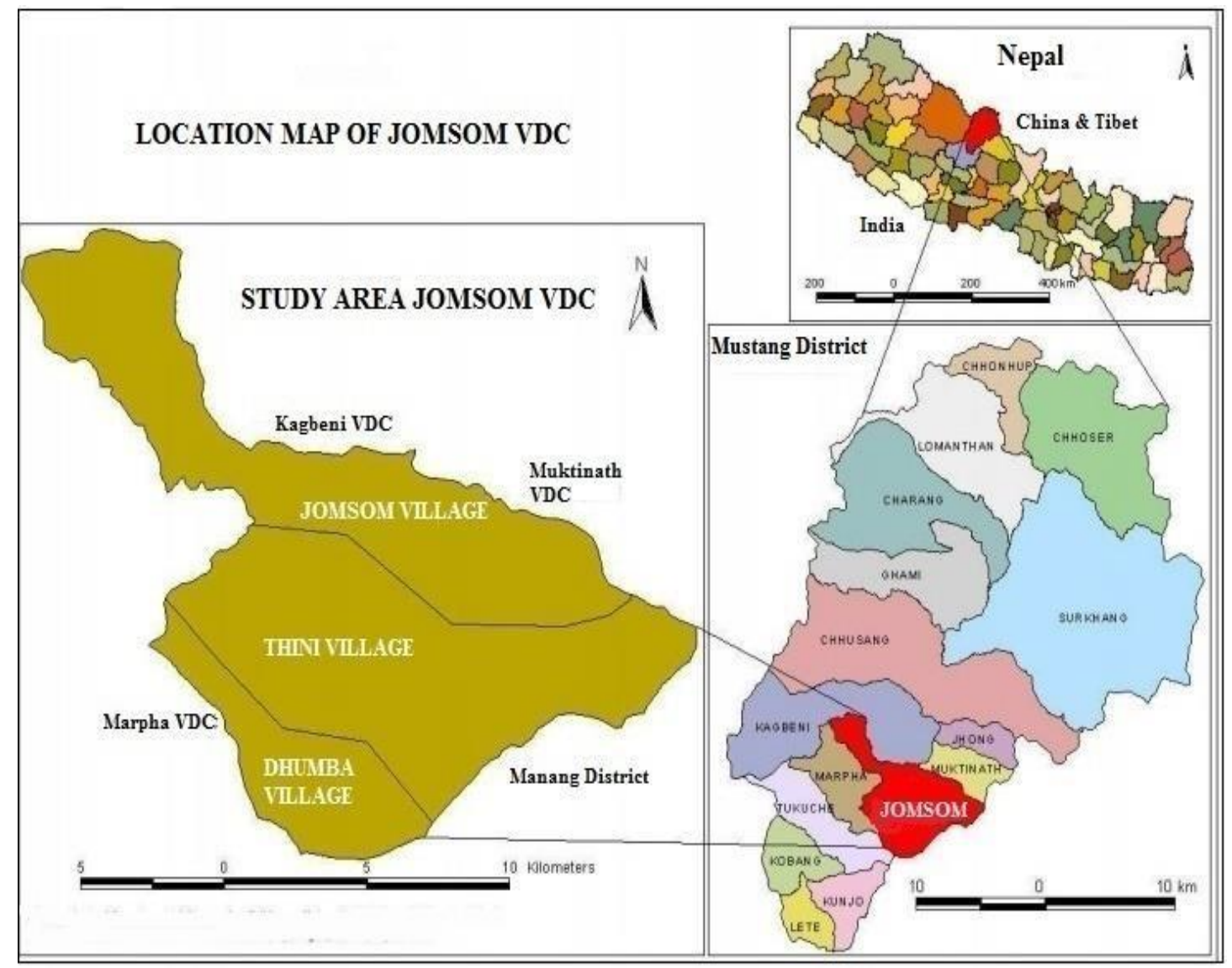

Fig 1

Source: Central Department of Geography, TU, Kathmandu, Nepal 
Total population of the Jomsom VDC is 1370 which comprises of 702 male and 668 female with 429 with households.

$>$ Demographic Composition of Jomsom

\begin{tabular}{|c|c|c|c|c|}
\hline Ethinicity & Population & Percentage & Male & Female \\
\hline Thakali & 403 & 29.42 & 184 & 219 \\
\hline Gurung & 244 & 17.48 & 113 & 131 \\
\hline Dalit & 205 & 14.96 & 101 & 73 \\
\hline Magar & 167 & 12.19 & 94 & 60 \\
\hline Brahmin/Chettri & 150 & 10.94 & 90 & 53 \\
\hline Tamang & 88 & 6.42 & 35 & 28 \\
\hline Others & 113 & 8.24 & 702 & 668 \\
\hline Total & 1370 & 100 & & \\
\hline
\end{tabular}

Table 1

Source: National Census, 2011

In 2005, the National Planning Commission decided to support connecting Manang and Mustang district with Nepal's road network, as part of the government's poverty reduction strategy of the 10th Five Year Plan (2002- 2007). Construction of Beni-Jomsom rural road was included as Priority 1 project in the government's Medium Term Expenditure Framework, and deployed Nepal Army to construct the road in year 058 and was completed in 066 with the construction cost of about 60 crores 10 lakhs. The road was handed over to the Department of Road in year 067. From Pokhara, this $4.5 \mathrm{~m}$ wide road corridor follows the Kali Gandaki River and connects Myagdi district to district headquarter Jomsom and extends towards Muktinath and Korolla. It is among the only two feeder roads of the district and is categorized as a Rural Road Class A. The total length of the road is 76 kilometers and is all earthen. It covers Ghasa, Lete, Kobang, Tukuche, Marpha, and Jomsom service centers within the Mustang district (DDC, 2013). A well-developed transport and communications infrastructure network is a prerequisite for the access of less-develop communities to core economic activities and services. Infrastructure development is one of the major factors contributing to overall socio-economic development. In this context, this article focused to explore the influence of road in the service delivery process, communication system, indigenous practices, and environment in Jomsom which lies in the trans-Himalayan region having unique socio-cultural setting and geographical setting.

\section{OBJECTIVE AND METHOD}

The main objective of this article is to find out the influence of road in interaction patterns, service delivery, indigenous practices, and the environment in mountain regions. For this, the information is carried out through comprehensive fieldwork to Jomsom rural municipality of Mustang district which represents the high mountain region of Nepal. This article is based on a qualitative research approach. Both primary and secondary data are used. Primary data are collected by the case study method. Secondary data are collected from previous literature through content analysis. The content analysis method is used to analyze both primary and secondary data.

\section{THEORETICAL DISCOURSE}

According to Cochrane (2000), Globalists see globalization as an inevitable development which cannot be resisted or significantly influenced by human intervention, particularly through traditional political institutions, such as nation-states. Traditionalists argue that the significance of globalization as a new phase has been exaggerated. They believe that most economic and social activity is regional, rather than global, and still see a significant role for nationstates. Transformationalists believe that globalization represents a significant shift, but question the inevitability of its impacts. They argue that there is still significant scope for national local and other agencies (Servaes, 2007).

Sustainable development is a process in which the exploitation of resources, the direction of investments, and institutional changes are made consistent with future as well as present needs. Sustainable development must, therefore, meet the needs of the present generation without comprising the ability of future generations to meet their own aspirations and needs. Sustainable development requires pragmatic management of natural resources through positive and realistic planning that balances human expectations with ecosystem's carrying capacity. It aims not only at long term sustainability of the natural resource base but also economic efficiency in resources utilization (Bongartz, 1998). In the post-cold war era, the subject of environment and sustainable development has become perhaps the most important issue both nationally and internationally. Nepal has to consider issues relating to environment and sustainable development from the point of view of its own unique situation and the resources which it is in a position to mobilize at local, national, regional and international donors level (Bhargava, 1998). The high Himalaya is geographically an extremely young and unstable area. Massive erosion is a natural phenomenon under these conditions and the macro effects of erosion and hydrology-both within the hills (Bongartz, 1998). 


\section{FINDINGS AND DISCUSSION}

\section{$>$ Women empowerment}

Lack of time is a key constraint on the ability of women to build their assets and reduce their vulnerability. By reducing the burden of transport, development projects can increase women's productivity and income and also enhance their assets. This would also give women more time to rest, enjoy social life, and participate in community activities (www.bioone.org).

Case 9 remembered the days when they were not allowed to enter the houses and were allowed only laborious jobs. But now with the arrival of road the awareness level of the people of all caste regarding laws and litigation on racial discrimination increased, Dalits also became more aware about the importance of education and income level of Dalit along with awareness increased. Her husband also told he has also left drinking alcohol before 4 years because he became aware about its negative impact on health and he gets less free time these days. She is happy that now the social discrimination among higher and lower caste in area is almost zero. She proudly says that people of area elected her as a member of rural municipality and now she sits and eats together with all the other members in meetings and programs. Similarly, Case 12 told during past days female were not allowed to sit in the meetings of village. She remembers the day when she was disallowed by Mukhiya to enter the meeting of village which is held in Sharawan 7 of every year. After the struggle and follow up from Women's Group and rise in awareness level now female also participates in such meetings since 4year back. From this year minimum 3 female are also made compulsion in body of Mukhiya of village. Mentioned information of case 9 and 12, women involvement and participation is enhanced by the road transportation. Gurung(2010) is also argued that Ethnically and socially marginalized groups could especially benefit from local capacity development and the strengthening of selfcapacities, when appropriately addressed by social inclusive approach. So construction of rural road for the accessibility is to open door of stream line development in rural remote area which is also the base of inclusive governance.

\section{$>$ Community Participation}

According to United Nations Development Programme (1993) participation means that people are closely involved in the economic, sociocultural and political processes that affect their lives.\| Participation in development is usually said to mean the full involvement of the people in development which affect their lives regardless of gender, race, age, class, sexual orientation or disability (http://shodhganga.inflibnet).

Mukhiya (Case 15) is the eldest leader of village who has been selected by representation of all villages on mutual agreement and till date none of the Mukhiya has been accused of any negative practices. The prolongation of rich social bonding, preservation of culture, tradition and rich natural resources of Mustang till date is due to the
Mukhiya $a^{6}$ trend that is why Mukhiya trend is pride of Mustang so it should be continued and preserved with modification as per need of time, he added. Community participation was a necessity in past because of the area was isolated before road but after the opening of Baglung Jomsom rural road (BJRR) although the awareness level of the people increased but due to busy life style and open access of the resources these days people have less time for participating in the community works.

\section{$>$ Influence on indigenous practices}

The development of roads breaks the cultural barriers among the communities by bringing them together more frequently for interaction, understanding and exchange of ideas. Thus the cultural reservations are broken and acculturation takes place (http://pmgsy.nic.in).

Case 4 told being a middle son of family he was obliged to stay as lama (monk) during his childhood. He started his period of lama from age of 11 despite of his dissatisfaction after the threat from the community to boycott him from society and family. Later on he gave up from studying the lama for which he is paying penalty every year and for every holy function. Now after road rise in awareness level and easy availability of means of family planning has reduced the family size to just two children "s which has hampered this cultural trend enormously. He adds with the rapid rate of modernization it's time to rethink and improvise these types of cultural practices in the society Similarly, case 3 told that road has made easier in cultural exchange, preservation and boosted social harmony. He added the way the Mukhiya is selected is same as before, the practice of Jhomgi (party within village), playing tara (traditional archery) etc has not changed. He shared now he can travel to Tukuche within half an hour for paying the tiro (tax) to Mukhiya of Tukuche, he can go to Marpha within 15 minutes for playing Tara. Case said before the road people in area were only Buddhist and Hindu religion but after arrival of road the certain people started following Christian, Shahi and other religions too. Today children are fond of celebrating birthday and cutting cake on birthday. With the increasing homogeneity in the society the rate of social crime is increasing in the area, nowadays everyone puts the padlock in the door which was not common in past. Case 10 also told BJRR has made easy access of donors and ease in construction and preservation of historical monuments like monasteries and temples. He shared, 400 years old Thini monastery has been recently renovated and donor of other one is also planning to reconstruct 600 year's old Khusupterunga monastery. During local archery competitions more use of modern archery equipment is seen he is not happy with this trend. He added in past Bhadra mela festival was celebrated just showing traditional dances and drinking alcohols but these days'awareness programs are given more priority in such cultural events. He told they are running Thakali language classes in village. In Dashain festival people used to come community hall to take blessing from all the elders gathered in hall but this practice has gone down and people has 
started celebrating Dashain in their own houses like in nearby cities, he added.

From above information of cases it can be concluded that culture and traditions of the area has also been influence by BJRR. The traditional and religious practices have been affected by the road with the growing rate of modernization and increased awareness like in case of Jhuma tradition and way the festivals are celebrated. Due to easy access and cheap availability of materials historical and religious monuments are reconstructed and rehabilitated and traditional mud houses are now replaces by RCC houses. It is seen that in the area after road the awareness of people for the preservation of culture has increased. Road has helped in promotion of the local cultures and has made easier in cultural exchange, preservation of culture and monuments.

\section{$>$ Interaction Pattern}

Road transportation connects different areas of geography. It support to interact between different sociocultural groups of that geographical area. Jomsom is also tied up in the interaction level by the Baglung Jomsom Rural Road. Case 7 told before road the communication with his family in Pokhara was very difficult the only means of communication was through letter and a telegraph service later operated by Nepal Telecom. Later with the road access and extension of communication services now he owns a mobile phone sent by his son from Pokhara and happy that now flow of information is easier in any emergencies Similarly, case 5 told in past when he used to get newspaper from airplane while distributing to houses people used to tell him who will read these papers by paying now scenario has changed when paper gets delayed by 5 hour people calls him and complains to supply on time this is all because of the rise in awareness level after road. After road more than 3 local newspapers, many media persons, one highly sophisticated FM station, cable television are established in district which in turn has contributed in reducing the corruption, increasing quality of development works, increasing social awareness etc.

Mentioned facts of cases reflects that road has contributed in shift and transformation of indigenous technology. Those indigenous technologies which were insufficient and less productive are now replaced by new modern technologies after BJRR. Similarly, BJRR connectivity has emerged as analogous to information technology connectivity and it has helped in empowerment and breaking the isolation peoples of the study area

\section{$>$ Rural Road and Service Delivery}

One of the major benefits to the poor of an improved rural road is their ability to better access state services, in particular health facilities and personnel. Improved rural roads create the conditions for better access of people to services, and of services to the village. They also facilitate the reach of the state into new areas (Hettige, 2006).
Case 1 told before road the availability of the doctor in the hospital was throughout the year but they were less motivated but now although the movement of the doctor to the nearby cities and their home is frequent they are highly motivated and are more aware and knowledge full with the modern practices in the medical field. Before road patient used to stay at hospital for two three months until they were totally cured now stay of patient has decreased hugely due to ease in movement. Services provided by organization like ACAP, Jigme foundation etc. has been improved after road due to ease monitoring by concerned agencies. She admits that service delivery to remotest villages has been made easier and health post are established in very villages after the opening of road due to road recently for the first time she went for the health camp in the farthest village Lomanthang of the district which would not have been possible without road. Similarly, case 6 told road access has made easier to get technical support from the concerned offices easier. Case 12 admits that road and introduction of technology after road has made easier and faster in service delivery. In past the quality of development works was good and technicians and service providers were more responsible and dedicated to works when they travel to each site they used to stay stand by in site until the work gets completed but now after road, movement of the technicians/ staff is frequent they are more interested in finishing the works as fast as possible and returning back home which in turn reduced the quality of work.

From the facts of the above cases, it can be concluded that opening of BJRR in study area has been able to bring service provider nearer to people and made service delivery effective and efficient. Officials are reported higher motivation to do their jobs, and some were able to take up secondary occupations to supplement their incomes because of the time saving through better transport. Education health and development sector officials in Jomsom reported that it is now easier to monitor the provision of services in the field with the use of motorcycles or public transport. Discussion with the governmental officers indicated that service delivery has become efficient and effective after road and told demands for different kinds of developmental programmes have increased significantly as it become easier for service receiver to reach service providers in the district.

\section{$>$ Rural road and rural environment}

Transport infrastructure provides a basis for economic activities in the rural areas in the long term. But the environment consequences cannot be neglected only foreseeing long term economic benefit. With its approach of constructing rural roads considering environment and rural poverty alleviation measures, the development activities with potential of economic benefit were liable to carried serious risk of environmental adversities. Environment considerations were undermined because it was considered constraints to development. But the result of past negligence of environment is seen today. Losses of land, siltation, landslides, soil erosion, and loss of biodiversity are some of the adverse consequences (Mulmi, 2009). 
Case 2 is also similar to Mulmi(2009) and said different types of diseases and insects are seen these days in agriculture field and at household and high dust pollution from the vehicles have turned the green leaves of apples into brown. Similarly Case number 3 told dust pollution is the major nuisance to the local people and tourists after opening of BJRR. Similarly Case 14 told these days the bluish sky of past has changed to humid most of the time. Case 4 told that the green leaves of the apples trees along road alignment are all covered with the dust. Similarly case that the rate of respiratory disease is increasing among the locals due to pollution from the vehicles. As per Case 4 management of solid waste is the major challenge and with the flow of more number of tourist's pollution in Kaligandaki River is increasing. Case 15 expressed the management of the scattered wastes in the area is a major challenge. Increased number of tourists and vehicles everyday has increased the volume of wastes and garbage, therefore awareness visibility boards, dustbins and modern waste management site should be established as soonest possible. Case 6 told mosquitoes which was rare before road in study area is common these days. Case 15 told extension of right of way is major problem along the Beni Jomsom road alignment since most of human settlement like in Lete, Tukuche and Jomsom area, so it should be monitored well and 20 meter right of way must be cleared as soon since blacktopping and extension works is ongoing. Government should formulate right policy to compensate the houses falling under right of way for their resettlement, since main market area of VDC including more than $80 \%$ of hotels falls under. Similarly Case 14 told with the increasing opportunities the congestion in the area along the alignment has increased, therefore it's now time to formulate plan use plan of area and manage the area according to the plan. The increased congestion with unmanaged parking of vehicles is also added problem after road. Case 13 told only limited number of vehicles should be allowed as per holding capacity of area to reduce congestion and protect its natural beauty. Case 15 told with the road access homeless peoples and beggars from nearby city is increasing in area so concerned agencies must take action to manage this problem.

Similarly, case 7 told during opening of road due to excessive use of machines the area is in high risk landslide and erosion therefore retaining structures and river training works along Kaligandkai area is very much essential to protect the settlement. Similarly, Case 8 said scarcity of water in the major problem in village which she thinks is due to settlement of water source and formation of cracks during excavation of road and seepage due to vibration from vehicles later. Case added soil erosion and landslide is also frequent these days in village during the monsoon therefore protective measures must be given high priority.

The construction of the Baglung Jomsom Rural Road began in year 2058 B.S by deploying Nepalese Army. It has a rough terrain and gravel and rocky geology. The use of the rock blasting and bulldozers was high during construction, as the tremor effect landslides and erosion is high along the alignment. Since in past road was constructed along the alignment of existing popular trekking trail dust pollution from the vehicles is the major problem for the trekkers these days. Therefore present environment status of the road and the changed observed in the area due to the construction of the road are highly important for the future development planning in the area.

\section{CONCLUSION}

Interlinking of the road, impacts are seen in two dimensions. On one side, Women empowerment, the pattern of social interactions, community participation are positively influenced. Women's participation, communal responsibility is increased after linking the road in Jomsom. Similarly, superstitions and traditional practices are also in changing paths. These facts are partially analog to theoretical interpretation of Cochrane (2000). But on the other side, so many negative impacts are seen in environmental sectors. Landslide. Soil erosion, dust, and sound pollution are increased by the inter-link of the road in the Jomsom area. For sustainable development, road projects should be managed to the pattern of adaptation environment which is analog to theoretical interpretation of Bongartz(1998) and Bhargava(1998). So concluded that road transportation positively influenced in social sectors but environment sectors are negatively influenced in the mountain regions.

\section{REFERENCES}

[1]. Bhargavava, K. K (1998). "Environment and Sustainable Development: A Note". Environment and Sustainable Development: Nepal Foundation For Advanced Studies (NEFAS), Friedrich-EbertStiftung(FES)

[2]. Bongartz, H. (1998). "Environment and Sustainable Development: An Observation", Environment and Sustainable Development: Nepal Foundation for Advanced Studies (NEFAS), Friedrich-Ebert-Stiftung (FES)

[3]. Cochrane, A. and K. Pain "A Globalizing Society?" In David Held(ed).A globalizing World? Culture, Economic, Politics, pp.5-45.London: Routledge in association with the open university.

[4]. District Development Committee. (2013). District Transport Master Plan. Mustang: DDC.

[5]. District Development Committee. (2059). District Profile of Mustang District 2059. Mustang: DDC.

[6]. Golmohammadi, F (2012). Rural Roads, Sustainable Development and Maintenance of People in Desert Regions; Case Study: South Khorasan Province-East of Iran. Iran: International Journal of Science and Engineering Investigations.

[7]. GON. (2017). Transportation Sector Profile. Kathmandu: Investment Board Nepal, Office of the Investment Board.

[8]. Gurung, N. S. (2010). Community -Led Rural Road Construction in Nepal. Occasional Paper. Future Generations Graduate School. 
[9]. Hettige, H. (2006). When Do Rural Roads Benefit the Poor and How? Asian Development Bank. Philippines: Library of Congress Cataloging-in Publication Dat.

[10]. LGCDP. (2011). Economic Analysis of Local Government Investment in Rural Roads in Nepal. Kathmandu: Ministry Of Local Development. UNDP.

[11]. Mulmi, A. D. (2009). Green road Approach in Rural Road Construction for the Sustainable Development of Nepal. Kathmandu: Department of Roads, Ministry of Physical Planning and Works.

[12]. NPC. (2011). Nepal Status Paper United Nations Conference on Sustainable Development 2012 (Rio+20). Kathmandu: Government of Nepal, National Planning Commission.

[13]. Servaes, J. (ed.2007). Communication for Development and Social Change, Vivek Mehra for SAGE Publication India Pvt Ltd Delhi

[14]. USAID. (2008). Roads Socio-Economic Impact Assessment. Afghanistan Services under Program and Project Offices for Results Tracking (SUPPORT) Program.

[15]. Van de Walle, D. (2008). Impact Evaluation of Rural Road Projects. Norwegian Trust Fund for Impact Evaluation in Infrastructure.

[16]. www.bioone.org/doi/full/10.1659/02764741(2002)02 2\%5B0221:TIOIRR\%5D2.0.CO \%3B2 (assessed on $7^{\text {th }}$ February 2018). www.pmgsy.nic.in/pmg932.asp (assessed on $8^{\text {th }}$ February 2018).

[17]. www.shodhganga.inflibnet.ac.in/bitstream/10603/407 29/14/14_chapter\%205.pdf (assessed on $8^{\text {th }}$ February 2018). 